\title{
A CYP24A1 Gene Mutation: A Rare Cause of Adult Onset Recurrent Nephrolithiasis
}

\author{
Jamila A Benmoussa ${ }^{1,2^{*}}$, Grace Y Kim², Hassan Shawa ${ }^{2}$ \\ ${ }^{1}$ Diabetes and Endocrine Care Department, St Peter's Hospital, Albany, New York 12204 \\ ${ }^{2}$ Division of Endocrinology and Metabolism, Albany Medical College, Albany, New York 12208
}

\begin{abstract}
$\underline{\text { Abstract }}$
CYP24A1 homozygous gene mutation is a well-known cause of infantile hypercalcemia and adult onset hypercalcemia/nephrocalcinosis. A mutation in this gene causes the loss of function of 24 hydroxylase enzyme that is essential for the catabolism of vitamin D metabolites.

We describe a rare case of a 35 -year-old man with recurrent nephrolithiasis carrying two heterozygous variants of the CYP24A1 gene. He had recurrent nephrolithiasis as adult without hypercalcemia as child. He has strong family history of kidney stones. Biochemical work up showed hypercalcemia, hypercalciuria, high 1,25-dihydroxyvitamin D and low parathyroid hormone level. Hypercalciuria and recurrent nephrolithiasis resolved with thiazide diuretic without worsening in serum hypercalcemia.

CYP24A1 inactivation mutations should be suspected in adults with personal and family history of recurrent nephrolithiasis if they present with non PTH-mediated hypercalcemia and/or hypercalciuria and elevated 1,25-dihydroxyvitamin D level even without a history of hypercalcemia during childhood. Thiazide diuretic may be used for its management safely.
\end{abstract}

\section{Introduction}

The prevalence of vitamin $\mathrm{D}$-mediated hypercalcemia is unknown, but currently increasing due to increase in vitamin $\mathrm{D}$ supplementation and increase detection of cytochrome P450 24A1 (CYP24A1) mutations [1]. We present a patient with recurrent nephrolithiasis with hypercalciuria and elevated 1,25-dihydroxyvitamin D3 $\left(1,25-(\mathrm{OH})_{2} \mathrm{D}_{3}\right)$ level without a history of hypercalcemia nor nephrolithiasis during childhood associated with two variants of heterozygous CYP24A1 mutations.

\section{Case Presentation}

A 35-year-old man presented with a complaint of recurrent nephrolithiasis. He has significant medical history of multiple episodes of nephrolithiasis since the age of 21 that required multiple laser lithotripsy and ureteral stent placement (stone analysis showed calcium oxalate). He also has a family history of recurrent kidney stone in his mother, maternal grandmother, sister, father and paternal aunt. No lab work or genetic testing is available for any family members. Patient denied the use of vitamin $\mathrm{D}$, calcium supplement or any medications. His physical examination including vital signs were unremarkable. Biochemical work up was remarkable for hypercalcemia, hypercalciuria and elevated $1,25-(\mathrm{OH})_{2} \mathrm{D}_{3}$ (Table 1$)$. 


\begin{tabular}{|c|c|c|c|c|c|c|c|c|c|c|}
\hline & $\begin{array}{l}\text { Calcium } \\
(\text { nl. 8.6- } \\
10.3 \mathrm{mg} / \\
\text { dL) }\end{array}$ & $\begin{array}{l}\text { Ionized } \\
\text { Calcium } \\
(\text { nl.1.2-1.32 } \\
\text { milli- } \\
\mathrm{mol} / \mathrm{L})\end{array}$ & $\begin{array}{l}\text { 24-hours } \\
\text { urine calci- } \\
\text { um } \\
(\text { nl. }<300 \\
\text { mg/24hr), }\end{array}$ & $\begin{array}{l}25(\mathrm{OH}) \\
\mathrm{D}_{3} \\
(\mathrm{nl} . \\
21-50 \\
\mathrm{ng} / \mathrm{mL})\end{array}$ & $\begin{array}{l}1,25-(\mathrm{OH})_{2} \mathrm{D}_{3} \\
(\mathrm{nl} .10 .0-75.0 \\
\mathrm{pg} / \mathrm{mL})\end{array}$ & $\begin{array}{l}\text { PTH } \\
(\text { nl. } 14 \\
-72 \text { pg/ } \\
\text { mL) }\end{array}$ & $\begin{array}{l}\text { Phos- } \\
\text { phorus } \\
\text { (nl. 2.4- } \\
4,7 \text { mg/ } \\
\text { dL) }\end{array}$ & $\begin{array}{l}\text { Albumin } \\
(\mathrm{g} / \mathrm{dL})\end{array}$ & $\begin{array}{l}\text { Creat- } \\
\text { inine } \\
(\mathrm{mg} / \\
\mathrm{dL})\end{array}$ & $\begin{array}{l}\text { GFR } \\
(\mathrm{ml} / \\
\mathrm{min})\end{array}$ \\
\hline $\begin{array}{l}\text { At the } \\
\text { time of } \\
\text { diagnosis }\end{array}$ & 10.6 & 1.40 & 421 & 20.4 & 170 & 6.3 & 2.7 & 4 & 0.8 & $>60$ \\
\hline $\begin{array}{l}\text { Post } \\
\text { HCTZ }\end{array}$ & 8.4-9.6 & 1.28 & 206 & 21 & 109 & 12.4 & 2.6 & 4 & 0.9 & $>60$ \\
\hline
\end{tabular}

Abbreviations: HCTZ: hydrochlorothiazide, GFR: Glomerular filtration rate

Table 1: Patient's biochemical findings at the time of diagnosis and after starting hydrochlorothiazide

Extensive workup for granulomatous, infectious, autoimmune diseases and malignancies was negative. CT abdomen and pelvis showed obstructing $6 \mathrm{~mm}$ left ureteropelvic junction calculus resulting in acute mild-moderate left hydronephrosis and multiple bilateral non- obstructing renal calculi measuring 1-6 mm. Dual-energy X-ray absorptiometry (DXA) showed a normal bone mineral density for age. Genetic testing revealed two heterozygous variants of CYP24A1 gene mutation of unknown significance, first heterogenous variant was C/A change within coding exon 3 and (c.469C>A), second a heterozygous variant in intron 3. 25-hydroxyvitamin D3 25(OH) $\mathrm{D}_{3}: 24,25$-dihydroxyvitamin D3 $\left(24,25-(\mathrm{OH})_{2} \mathrm{D}_{3}\right)$ ratio was 55 .

The patient was advised against prolonged sun exposure, vitamin D/ calcium supplements and was encouraged to increase oral hydration. He was started on hydrochlorothiazide $12.5 \mathrm{mg}$ daily which resolved the hypercalciuria without worsening in serum calcium level. His kidney function remained stable without further recurrent kidney stone. A kidney Ultrasound one year later was negative of stones.

\section{$\underline{\text { Discussion }}$}

We herein report an adult patient with a personal and family history of recurrent nephrolithiasis with non-parathyroid hormone (PTH)-mediated hypercalcemia and hypercalciuria as well as an elevated $1,25-(\mathrm{OH})_{2} \mathrm{D}_{3}$ level without a history of hypercalcemia nor nephrolithiasis during childhood. Genetic testing revealed two heterozygous variants of CYP24A1 of unknown significance. He responded well to thiazide diuretic without worsening in serum calcium.

Vitamin D-mediated hypercalcemia is one of the causes of PTH-independent hypercalcemia (Table 2) [1].

Vitamin D plays an important role in hemostasis of calcium through increase calcium absorption in the intestines and enhancing release of calcium out of the bone, but first it should be in the active form. It is hydroxylated to $25(\mathrm{OH}) \mathrm{D} 3$ in the liver, then again to $1,25-(\mathrm{OH}) 2 \mathrm{D} 3$ in the kidneys. Vitamin D activation is regulated by the PTH, calcium and vitamin D metabolite levels. CYP24A1 encode for 24 $\alpha$-hydroxylase responsible for the inactivation of $1,25-(\mathrm{OH}) 2 \mathrm{D} 3$ to 1,24,25-trihydroxyvitamin D3 (1,24,25-(OH)3D3) and 25(OH)D3 to $24,25-(\mathrm{OH}) 2 \mathrm{D} 3$ when it is no longer needed (Figure 1) $[2,3]$. 


\section{Malignancy:}

- $\quad$ PTH-related peptide

- $\quad 1,25-(\mathrm{OH})_{2} \mathrm{D}_{3}$ mediated

- $\quad$ Cytokine Mediated (Osteoclast-activating factor)

- $\quad$ Lytic bone metastases

\section{Vitamin D mediated:}

\section{- Excessive cholecalciferol, ergocalciferol, or calcitriol indigestion}

\section{- Ectopic 1,25- $(\mathrm{OH})_{2} \mathrm{D}_{3}$ production}

- Granulomatous disease: Sarcoidosis, Tuberculosis, Histoplasmosis, Coccidioidomycosis, Leprosy

- Lymphoma

\section{- Inactivating mutations of the CYP24A1 gene}

Endocrine:

- Hyperthyroidism

- Pheochromocytoma

- Adrenal Insufficiency

- Vasointestinal polypeptide hormone-producing tumors

\section{Medications: \\ - Milk-alkali syndrome \\ - Vitamin-A toxicity \\ - Vitamin-D toxicity}

\section{Others:}

- Immobilization

- Acute renal failure

Abbreviations: PTH: parathyroid hormone; 1,25- $(\mathrm{OH}) 2 \mathrm{D} 3$ : 1,25-dihydroxyvitamin D3; CYP24A1: Cytochrome P450 24A1.

Table 2: Differential diagnosis of confirmed PTH-independent hypercalcemia (Adapted form [1])

The loss of function of the CYP24A1 gene mutation leads to Idiopathic Infantile Hypercalcemia (IIH) and Adult Onset Nephrocalcinosis (AON) [2]. Loss of function mutations of CYP24A1 cause 24 a-hydroxylase deficiency which results in vitamin $\mathrm{D}$ metabolites accumulation leading to hypercalcemia and nephrocalcinosis $[3,4]$. IIH was first described in 1950 [3]. Affected patients showed a marked increase in vitamin $\mathrm{D}$ levels in response to exogenous vitamin $\mathrm{D}$ administration. In 2012, AON was described [5]. The clinical presen- tation usually includes recurrent nephrocalcinosis with polyuria and hypercalcemia. The degree of hypercalcemia can vary from mild and intermittent to severe but usually less pronounced then IHH. Other manifestations include neuropsychiatric symptoms, nausea, vomiting, constipation, hypertension $[2,6]$. It has been reported that vitamin D supplement and exposure to ultraviolet radiation cause worsening hypercalcemia in some patients [1].

The biochemical profile of vitamin D mediated hypercalcemia caused by loss of function mutations of CYP24A1 gene includes variable degrees of hypercalcemia, low to low normal PTH, high normal to high level of $1,25-(\mathrm{OH})_{2} \mathrm{D}_{3}$ level, $25(\mathrm{OH}) \mathrm{D}_{3}$ concentration can be low, normal or elevated [5]. 24,25- $(\mathrm{OH})_{2} \mathrm{D}_{3}$ is low because of reduced 24-hydroxylase activity. Despite the presence of adequate amounts of substrate, the ratio of $25(\mathrm{OH}) \mathrm{D}_{3}$ to $24,25-(\mathrm{OH}) 2 \mathrm{D}_{3}$ measured on a simultaneous sample is elevated which distinguishes it from cases of endogenous overproduction of $1,25-(\mathrm{OH})_{2} \mathrm{D}_{3}$ that may occur in granulomatous and lymphoma disorders. A $25(\mathrm{OH}) \mathrm{D}_{3} / 24,25$ $(\mathrm{OH})_{2} \mathrm{D}_{3}$ ratio of $7-35$ was observed in healthy subjects, whereas nearly all patients described to date with biallelic disease have a $25(\mathrm{OH}) \mathrm{D}_{3} / 24,25-(\mathrm{OH})_{2} \mathrm{D}_{3}$ ratio $>80$. Unaffected patients and most heterozygotes have a ratio $<30[1]$.

It was suggested that patients with IIH and AON have biallelic disease either homozygous or compound heterozygous mutations while patient with monoallelic gene mutation may be asymptomatic carriers or manifest a mild disease [1]. Cools et al reported results of genetic testing performed on members of an infant with known IIH revealed that six out of eight family members had heterozygous mutations of the CYP24A1 gene, though none had IIH. One subject did have documented kidney stones, and another two had subjective symptoms of renal stones. Therefore, it was concluded that heterozygous carriers have normal vitamin $\mathrm{D}$ levels and normal skeletal survey but were more prone to develop nephrocalcinosis [2]. Dinour, et al. reported three adult members of two Israeli families with severe nephrocalcinosis and laboratory findings like those found in IIH had loss of function of the CYP24A1 gene with a recessive mode of inheritance [6]. 


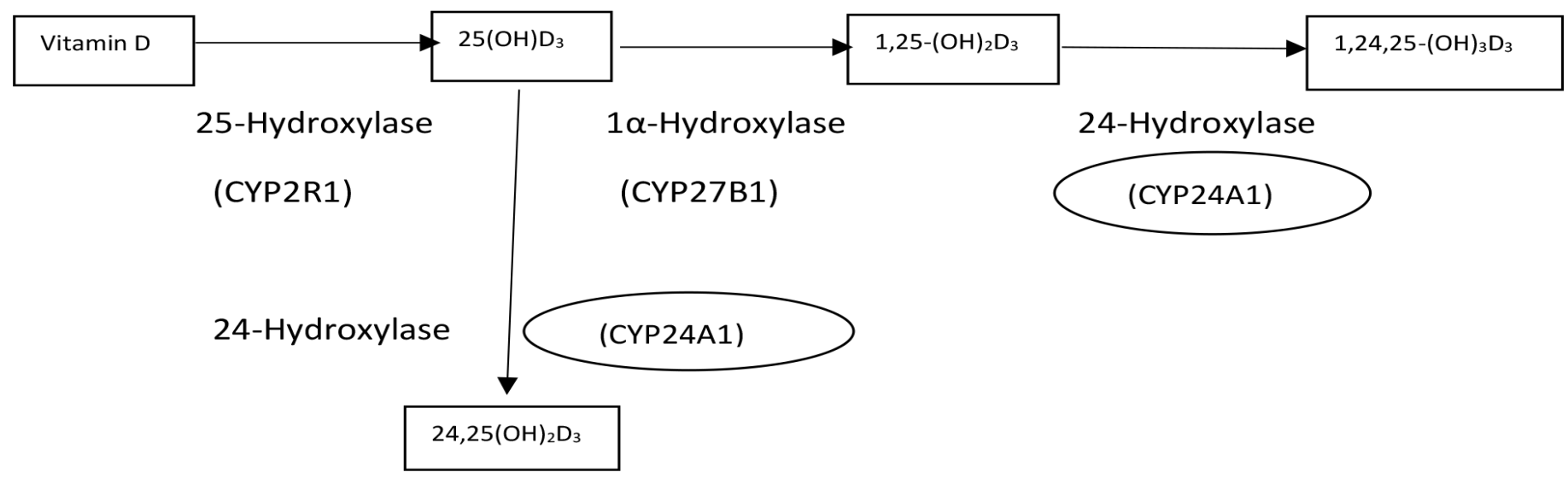

\begin{abstract}
Abbreviations: $25(\mathrm{OH}) \mathrm{D}_{3}$ : 25-hydroxyvitamin $\mathrm{D} 3$; 1,25- $(\mathrm{OH})_{2} \mathrm{D}_{3}: 1,25$-dihydroxyvitamin $\mathrm{D} 3$; 24,25- $(\mathrm{OH})_{2} \mathrm{D}_{3}: 24,25$-dihydroxyvitamin D3; 1,24,25-(OH) $\mathrm{D}_{3}$ : 1,24,25-trihydroxyvitamin D3; CYP24A1: Cytochrome P450 24A1; CYP2R1: Cytochrome P450 2R1; CYP27B1: Cytochrome P450 27B1.
\end{abstract}

Figure 1: Vitamin D metabolism pathway. Activation of Vitamin D: first occurs in the liver. Vitamin $\mathrm{D}$ is converted to $25(\mathrm{OH}) \mathrm{D}_{3}$ by the enzyme 25-hydroxylase. The CYP2R1 gene encodes 25 -hydroxylase. Second stage of activation occurs in the kidney. $25(\mathrm{OH}) \mathrm{D}_{3}$ is converted to $1,25-(\mathrm{OH})_{2} \mathrm{D}_{3}$ by the enzyme $1 \alpha$-hydroxylase. The CYP27B1 gene encodes $1 \alpha$-hydroxylase. $1,25-(\mathrm{OH})_{2} \mathrm{D}_{3}$ is the physiologically most active form of vitamin D3 which binds to the vitamin D receptor. Inactivation of Vitamin D: the enzyme 24-hydroxylase, which is encoded by the CYP24A1 gene catabolism of $1,25-(\mathrm{OH})_{2} \mathrm{D}_{3}$ to $1,24,25-(\mathrm{OH})_{3} \mathrm{D}_{3}$, and $25(\mathrm{OH}) \mathrm{D}_{3}$ to $24,25-(\mathrm{OH})_{2} \mathrm{D}_{3}$. (Adapted from [2,3])

Molin et al screened 72 hypercalcemic patients for CYP24A1 mutations and recruited 24 relatives and assessed their vitamin $\mathrm{D}$ metabolites. They found that patients with both allele mutations revealed the evidence of the loss of CYP24A1 activity but individuals with only one mutation had normal 24-hydroxylase enzyme activity [7].

Whether CYP24A1 mutations may be the only underlying cause in patients with suggestive biochemical profile is currently unknown. A recent mutation screen of CYP24A1 in two cohorts of renal stone-forming patients from the Northeast of England with biochemical profile suggestive for CYP24A1 deficiency revealed no pathogenic CYP24A1 mutations [8]. Such patients may have pathological variants outside the coding region of CYP24A1 (e.g., in the promoter region) or may have variants in other genes in the same pathway leading to similar pathophysiology, such as activating mutations in cytochrome P450 27B1 (CYP27B1) [9].

Long-term management of hypercalcemia and hypercalciuria due to inactivating CYP24A1 mutations aim to reduce hypercalciuria and thus nephrocalcinosis/nephrolithiasis. Decreasing calcium and vitamin $\mathrm{D}$ intake is sufficient for many patients. A variety of medications could be added if needed like glucocorticoids, loop and thiazide diuretics, phosphate supplementation, proton pump inhibitors and antifungal (ketoconazole and fluconazole) [1,5]. Thiazide diuretics decrease urine calcium excretion without exacerbation of hypercalcemia in most cases [1], as was the case in our patient.

In conclusion, CYP24A1 inactivation mutations should be suspected in adults with personal and family history of recurrent nephrolithiasis if they present with non PTH-mediated hypercalcemia and/or hypercalciuria and elevated 1,25-(OH)2D3 level even without a history of hypercalcemia during childhood. Genetic testing and recognition of disease can promote early diagnosis and treatment. Thiazide diuretic may be used for its management safely.

\section{Acknowledgements}

Authors declare none.

\section{Funding Statement}

None of the authors received any funding for this project.

\section{Conflict of Interest}

The authors declare that they have no conflicts of interest to disclose.

\section{$\underline{\text { References }}$}

1. Tebben PJ, Singh RJ, Kumar R (2016) Vitamin D-Mediatd hypercalcemia: mechanisms, Diagnosis, and treatment. Endocr Rev 37: 521-547. [Crossref]

2. Cools M, Goemaere S, Baetens D, Raes A, Desloovere A, et al. (2015) Calcium and bone homeostasis in heterozygous carriers of CYP24A1 mutations: A cross-sectional study. Bone 81: 89-96. [Crossref]

3. Schlingmann KP, Kaufmann M, Weber S, Irwin A, Goos C, et al. (2011) Mutations in CYP24A1 and Idiopathic Infantile Hypercalcemia. N Engl J Med 365: 410-421. [Crossref] 
4. Dusso AS, Gomez-Alonso C, Cannata-Andia J (2015) The hypercalcemia of CYP24A1 inactivation: new ways to improve diagnosis and treatment. Clin Kidney J 8: 456-458. [Crossref]

5. Tebben PJ, Milliner DS, Horst RL, Harris PC, Singh RJ, et al. (2012) Hypercalcemia, Hypercalciuria, and Elevated Calcitriol Concentrations with Autosomal Dominant Transmission Due to CYP24A1 Mutations: Effects of Ketoconazole Therapy. J Clin Endocrinol Metab 97: E423-E427. [Crossref]

6. Dinour D, Beckerman P, Ganon L, Tordjman K, Eisenstein Z, et al. (2013) Loss-of-Function Mutations of CYP24A1, the Vitamin D 24-hydroxylase Gene, Cause Long-standing Hypercalciuric Nephrolithiasis and Nephrocalcinosis. J Urol 190: 552-557.
[Crossref]

7. Molin A, Baudoin R, Kaufmann M, Souberbielle JC, Ryckewaert A, et al. (2015) CYP24A1 Mutations in a Cohort of Hypercalcemic Patients: Evidence for a Recessive Trait. J Clin Endocrinol Metab100: E1343-E1352. [Crossref]

8. Sayers J, Hypponen E, Rice SJ, Hogg P, Sayers JA (2013) Searching for CYP24A1 mutations in cohorts of patients with calcium nephrolithiasis. OA Nephrol 1: 1-6.

9. Dauber A, Nguyen TT, Sochett E, Cole DEC, Horst R, et al. (2012) Genetic Defect in CYP24A1, the Vitamin D 24-Hydroxylase Gene, in a Patient with Severe Infantile Hypercalcemia. J Clin Endocrinol Metab 97: E268-E274. [Crossref]

Copyright: (C) 2019 Benmoussa JA. This is an open-access article distributed under the terms of the Creative Commons Attribution License, which permits unrestricted use, distribution, and reproduction in any medium, provided the original author and source are credited. 